Systematic Review

\title{
Treatment of Neuropathic Pain Using Pulsed Radiofrequency: A Meta-analysis
}

\author{
Yu Shi, MD, and Wen Wu, MD
}

Zhujiang Hospital, Southern Medical University, China

Address Correspondence: Wen Wu, MD

Zhujiang Hospital, Southern

Medical University,

253 Industrial Avenue,

Guangzhou, China.

510282 China

E-mail:

wuwen66@163.com

Disclaimer: This work was supported

by National Natural

Science Foundation of

China (NNSFC), China;

Contract grant number:

81473769, Natural Science

Foundation of Guangdong

Province, China; Contract grant number: 2014A030313335.

Manuscript received: 11-19-2015 Revised manuscript received: 02-05-2016

Accepted for publication: 04-28-2016

Free full manuscript: www.painphysicianjournal.com
Background: Neuropathic pain (NP) is a major public health problem worldwide. Because of the unclear mechanism of NP, its treatment is one of the most difficult medical problems. As a targeted, noninvasive, safe therapy, pulsed radiofrequency (PRF) provides a new method for the treatment of NP; however, its effect on this treatment still lacks support from evidence-based medicine.

Objective: To conduct a meta-analysis of available randomized controlled trials and to evaluate the effectiveness and clinical utility of PRF for the treatment of NP.

Study Design: Meta-analysis.

Setting: All selected studies were randomized controlled trials.

Method: A systematic and comprehensive database search was performed of the PubMed, CENTRAL, EMBASE.com, Cochrane Library, Chinese Biomedical Literature, and Wanfang databases for literature published from the establishment of the databases to December 19, 2015. According to inclusion and exclusion criteria, the results of randomized controlled trials supporting PRF for NP treatment were collected. The risk of bias tool described in the Cochrane Handbook version 5.1.0 was used to assess the quality of each trial. Meta-analysis was performed using RevMan 5.3 software.

Results: A total of 12 randomized controlled trials involving 592 patients met the inclusion criteria. Overall, the results of the meta-analysis showed that, compared with the control group, PRF had a better effect on postherpetic neuralgia (PHN) in terms of pain score (one week, one month, and 3 months), excellent and good rate (one day, one month), and efficiency rate (one day). But PRF did not have a better effect on radicular pain in pain score (3 months). Side effects were less frequently found with the PRF treatment.

Limitations: Although we repeatedly tested the key words and used a manual method to prevent the loss of studies, due to the limitation of the included studies, some of the data were insufficient to complete the meta-analysis, and we were unable to obtain the original data from some studies. Some studies did not report the blind design, which decreased the quality of the current study.

Conclusion: PRF did not have a better effect on radicular pain, and PRF is an effective and safe therapeutic alternative for the analgesia of PHN. However, for a high recurrence rate over a long period, repeated PRF treatment has limitations.

Key words: Neuropathic pain, pulsed radiofrequency, analgesia, meta-analysis

Pain Physician 2016; 19:429-444 europathic pain (NP) is pain caused by damage or disease affecting the somatosensory nervous system (1). Neuropathic pain is associated with dysesthesia or allodynia. As a common clinical chronic pain, up to $7 \%$ to $8 \%$ of the European population is affected (2). Therefore, it is very important to find an effective treatment for NP. However, because the mechanisms that underlie the induction and 
maintenance of NP are not fully understood (3), NP can be very difficult to treat (4), and current treatments such as certain antidepressants, anticonvulsants, and topical lidocaine for NP have limited success $(5,6)$. Radiofrequency (RF), as a new method for the treatment of NP, has increasingly attracted people's attention (7).

In recent years, RF has usually been considered as a treatment option after conservative treatment has failed (7). RF treatments are currently categorized into continuous radiofrequency (CRF) and pulsed radiofrequency (PRF) (8). The main advantages of CRF treatment seem to be its effectiveness and high pain relief rate $(8,9)$. However, because of the exposure of nerve tissues to higher temperatures in CRF treatment (10), the disadvantages of this technique, such as numbness and anesthesia dolorosa $(9,11)$, have led clinicians to search for a better way to treat idiopathic NP. Sluijter et al (12) presented a PRF technique in which only short bursts of $\mathrm{RF}$ are applied to the nerve, and the tip temperature of the probe was only $42^{\circ} \mathrm{C}$. It was stated that there was no clinical evidence of neural damage and little postoperative soreness such as is often experienced after CRF. There have been some attempts to explain the influence of PRF on the nervous structure (13). One explanation is the induction of long-term depression in the spinal cord $(13,14)$. Another study has shown that PRF could reversibly disrupt the transmission of impulses across small unmyelinated fibers (15).

PRF treatment as a nondestructive technique is easily accepted by patients and clinicians because it treats NP by "modulation" rather than blocking pain signal transduction. Recently, PRF has been increasingly used in the treatment of some chronic pain conditions such as discogenic pain, lumbosacral radicular syndrome, chronic shoulder pain, lingual neuralgia, chronic breast neuropathic pain, and meralgia paresthetica (16-18), but its effect on the treatment of NP still lacks support from evidence-based medicine.

In this study, according to inclusion and exclusion criteria, the results of randomized controlled trials (RCTs) supporting the effect of PRF for NP treatment were collected. The results of this study may provide a reference for the clinical treatment of NP. Because of the obvious effect of CRF in NP treatment, studies related to CRF were excluded in the current study.

\section{Methods}

Our review followed the guidelines proposed by PRISMA (Preferred Reporting Items for Systematic Reviews and Meta-Analysis) (19).

\section{Eligibility Criteria}

Eligibility criteria are detailed in accordance with the PICOS (participants, interventions, controls, outcomes, and studies) framework.

\section{Participants \\ Participants were participants or patients with NP.}

\section{Interventions}

Participants or patients with NP had a PRF treatment.

\section{Controls}

Traditional treatment (basic drug treatment and nerve block treatment) control conditions were considered.

\section{Outcome}

The data pulled from each study included 1) basic information: author, year of publication, published magazines, the number of cases in each group, the proportion of men and women, average age, duration of follow-up time, study design; 2) statistical data: Visual Analogue Scale (VAS), Sleep Interference Score (SIS), Short form of the McGill pain questionnaire (SF$M P Q)$, dosage of oxycontin (Oxycontin), Excellent and good rate/efficiency rate, Self-Rating Depression Scale (SDS), Self-Rating Anxiety Scale (SAS), Dosage of NAISD (NAISD), the MOS 36-item Short Form health survey (SF-36), Medication Quantification Scale (MQS), Global Perceived Effect (GPE), Oswestry Disability Index (ODI), Numerical Rating Scale (NRS), pain medications, dosage of aspirin (Aspirin). In addition, excellent and good rate was defined as $\geq 50 \%$ decrease in pain score (a pain reduction $>50 \%$ is often reported in literature as a successful outcome), efficiency rate was defined as $\geq 30 \%$ decrease in pain score ( $>30 \%$ reduction is significant for clinical trials, especially if neuropathic features are taken into account) $(20,21)$.

\section{Studies}

RCTs including a comparative study were considered for inclusion.

\section{Search Strategy}

A systematic and comprehensive database search was performed of the PubMed, CENTRAL, EMBASE. com, Cochrane library, Chinese Biomedical Literature, and Wanfang databases for literature published from the establishment of the databases to December 19, 
2015 , with the following search terms in titles and abstracts: neuropathic pain, neurogenic pain, trigeminal neuralgia, dorsal root ganglion, occipital neuralgia, cervicogenic headache, lumbar radicular pain, lumbosacral radicular pain, thoracic postherpetic neuralgia and pulsed radiofrequency, pulsed radiofrequency treatment, pulsed radio frequency, and PRF. Filters were used to result in studies with human participants. There was no language limitation.

\section{Eligibility Criteria}

Studies were included if they (1) had a RCT design; (2) included patients with NP; (3) used PRF as an intervention; (4) used a traditional treatment such as drugs or nerve block as a control group. Meanwhile, studies were excluded if (1) they used CRF as a control group; (2) subjects were animals; (3) the study reported no data/results.

\section{Study Selection}

Two reviewers (Shi and $\mathrm{Wu}$ ) independently evaluated potentially eligible studies that were identified by our search. Articles were screened for eligibility based on a review of the title and abstract only, and disagreements were resolved by consensus. Of the articles remaining, their full text was accessed and read independently by the initial 2 reviewers. Consensus for inclusion was obtained with the help of a third party, when necessary. In addition, a manual analysis in order to prevent the loss of effective articles was necessary.

\section{Quality Assessment}

The internal validity of eligible trials was evaluated in accordance with a set of 7 criteria from the Cochrane Handbook (22): random sequence generation, allocation concealment, blinding of participants and personnel, blinding of outcome assessment, incomplete outcome data, selective outcome reporting, and other sources of bias (adequate description of sample size calculation and detailed disclosures of sources of funding). The judgements of bias were expressed as "low risk," "high risk," or "unclear risk." All divergences were resolved by consensus.

\section{Statistical Analysis}

For studies with data of sufficient quality and similar in simulation learning and outcome measures, we combined data in a meta-analysis in order to provide a pooled effect estimate. All data were entered into RevMan 5.3 (http://tech.cochrane.org/ revman/download), where standardized deviations and $95 \%$ confidence intervals (Cls) were calculated and pooled. The results were expressed as weighted mean difference (MD) with $95 \% \mathrm{Cl}$ for continuous outcomes and as an odds ratio (OR) with a $95 \% \mathrm{Cl}$ for dichotomous variables.

For each analysis, a heterogeneity test was performed using 12 statistics, which measures the extent of inconsistency among results and is interpreted approximately as the proportion of total variation across studies attributable to heterogeneity and not to chance. $12=25 \%$ was considered low, $50 \%$ moderate, and $75 \%$ high (22). 12 values higher than $50 \%$ were considered as having substantial heterogeneity, and the random-effects model was therefore applied for analysis of the data (22). In addition, we performed subgroup analysis according to prespecified variables, including study design and intervention characteristics (i.e., age, gender, test design, and test time). If there had been no statistical heterogeneity, we would have used a fixed-effect model. Subsequently, we performed subgroup analyses according to the study design. Design was chosen as a potential moderator because different designs were included in the metaanalysis and we considered it important to analyze by subgroup. To test for publication bias, a funnel plot, which graphs the effect size of each study according to its respective size effect (SE), was used. We assumed the existence of publication bias if there were no small studies with effect sizes favoring control groups. A two-tailed $P$-value of less than 0.05 was considered significant (22).

\section{Results}

\section{Study Selection}

The electronic database search of the PubMed, CENTRAL, EMBASE.com, Cochrane library, Chinese Biomedical Literature, and Wanfang databases provided a total of 2,870 citations, and 66 citations were found manually. After removing duplicate manuscripts, 2,778 studies remained. Of these, 2,548 were excluded based on the title and abstract review, leaving 230 for fulltext review. These 230 studies with their full text were retrieved and reviewed for eligibility, and 189 were excluded based on study design and outcome measures. This resulted in 41 studies that met all the criteria, and these were selected for inclusion. After being reviewed, a total of 12 articles were included in the final analysis (21,23-33) (Fig. 1). 


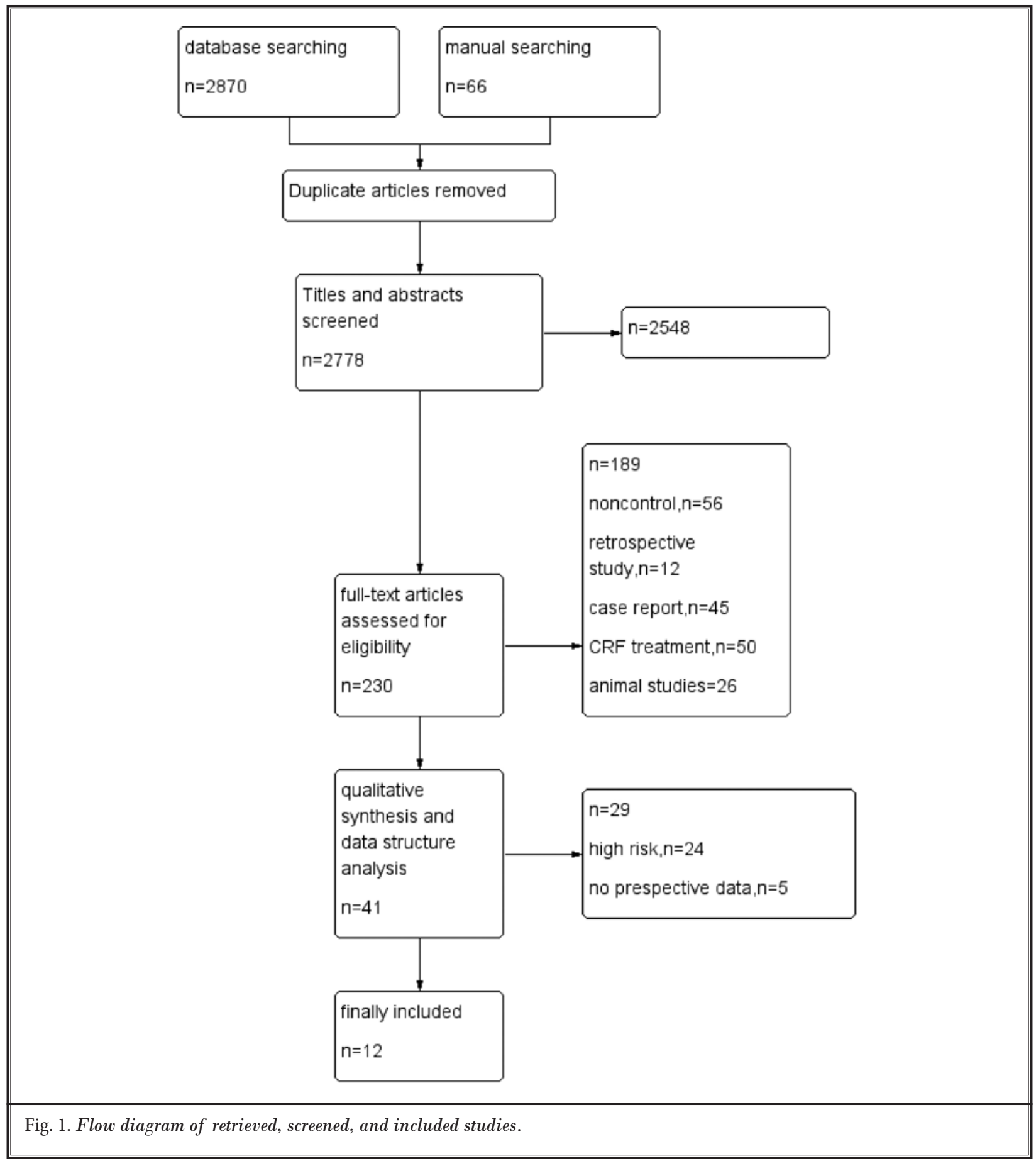

\section{Study Characteristics}

The selected studies included 592 cases, 304 cases in the treatment group and 288 cases in the control group, with 287 men and 305 women. The study dura- tion ranged from 3 months to 6 years, and the followup time was more than 3 months. Table I shows the basic characteristics of the included studies. 
Treatment of Neuropathic Pain Using Pulsed Radiofrequency

Table I. Basic characteristics of the included studies.

\begin{tabular}{|c|c|c|c|c|c|c|c|c|c|c|c|}
\hline Study & Al & B2 & Gender1 & Gender2 & Age1 & Age2 & Disease & T/C & Duration & Lost & Outcomes \\
\hline You et al, 2011 & 30 & 18 & $16 / 14$ & $10 / 8$ & $\geq 50 \pm 28$ & $\geq 50 \pm 17$ & PHN & PRF/NB & 1 y & 0 & 5 \\
\hline Liu et al, 2014 & 40 & 37 & $16 / 24$ & $17 / 20$ & $70 \pm 16$ & $64 \pm 15$ & PHN & PRF/BD & $6 \mathrm{~m}-3 \mathrm{y}$ & 3 & $1 / 2 / 3$ \\
\hline Huang et al, 2012 & 30 & 30 & $37 / 23$ & & $64.3 \pm 13.1$ & & PHN & PRF/BD & $4 \mathrm{~m}-6 \mathrm{y}$ & 0 & $1 / 4$ \\
\hline Deng et al, 2013 & 30 & 30 & $14 / 16$ & $13 / 17$ & & & PHN & PRF/NB & $3 \mathrm{~m}$ & 0 & $1 / 5 / 6 / 7$ \\
\hline Ke et al, 2013 & 48 & 48 & $25 / 23$ & $22 / 26$ & $73.04 \pm 6.5$ & $71.14 \pm 7.2$ & PHN & PRF/BD & $6 \mathrm{~m}$ & 4 & $1 / 8 / 9$ \\
\hline $\begin{array}{c}\text { Gabrhelík et al, } \\
2011\end{array}$ & 15 & 15 & $6 / 9$ & $7 / 8$ & $43.6 \pm 9.2$ & $45.9 \pm 12.8$ & CH & PRF/NB & $9 \mathrm{~m}$ & 0 & $1 / 10 / 11$ \\
\hline $\begin{array}{c}\text { Shanthanna et al, } \\
2014\end{array}$ & 16 & 15 & $10 / 6$ & $8 / 7$ & $62(45-85)$ & $57(35-83)$ & LRP & PRF/BD & $15 \mathrm{~m}$ & 2 & $1 / 12$ \\
\hline Fujii et al, 2012 & 16 & 11 & $9 / 7$ & $6 / 5$ & $66.6 \pm 18.2$ & $67.4 \pm 10.9$ & LSRP & PRF/NB & $1 \mathrm{y}$ & 0 & 1 \\
\hline Koh et al, 2014 & 31 & 31 & $11 / 20$ & $10 / 21$ & $65.97 \pm 7.2$ & $66.16 \pm 8.9$ & LRP & PRF/NB & $3 \mathrm{~m}$ & 0 & $10 / 11 / 12 / 13$ \\
\hline Zundert et al, 2007 & 11 & 12 & $5 / 6$ & $5 / 7$ & $42 \pm 12.2$ & $52.9 \pm 11.9$ & CRP & PRF/NB & $9 \mathrm{~m}$ & 0 & $1 / 9 / 11 / 14$ \\
\hline Yang et al, 2015 & 15 & 15 & $4 / 11$ & $3 / 12$ & $43.5 \pm 10.6$ & $39.2 \pm 9.3$ & CH & PRF/BD & $2 \mathrm{y}$ & 0 & $1 / 15$ \\
\hline Zhang et al, 2015 & 22 & 26 & $15 / 7$ & $18 / 8$ & $65 \pm 18$ & $61 \pm 18$ & LRP & PRF/BD & $3 \mathrm{y}$ & 0 & 1 \\
\hline \hline
\end{tabular}

A1: PRF, B2: control group; T/C: PRF/control; NB (Never block treatment), BD (Basic drug treatment). 1. VAS: Visual Analogue Scale; 2. SIS: Sleep Interference Score; 3. SF-MPQ: Short form of the McGill pain questionnaire; 4. Oxycontin: Dosage of OxyContin; 5. Excellent and good rate/efficiency rate; 6. SDS: Self-Rating Depression Scale; 7. SAS: Self-Rating Anxiety Scale; 8. Dosage of NAISD; 9. SF-36: the MOS 36-item Short Form health survey; 10. MQS: Medication Quantification Scale; 11. GPE: Global Perceived Effect; 12. ODI: Oswestry Disability Index; 13. NRS: Numerical Rating Scale; 14. Pain medications; and disability index; 15. Dosage of Aspirin; CH: Cervicogenic Headache; LRP: chronic lumbar radicular pain; LSRP: Lumbosacral Radicular Pain; CRP: chronic cervical radicular pain.

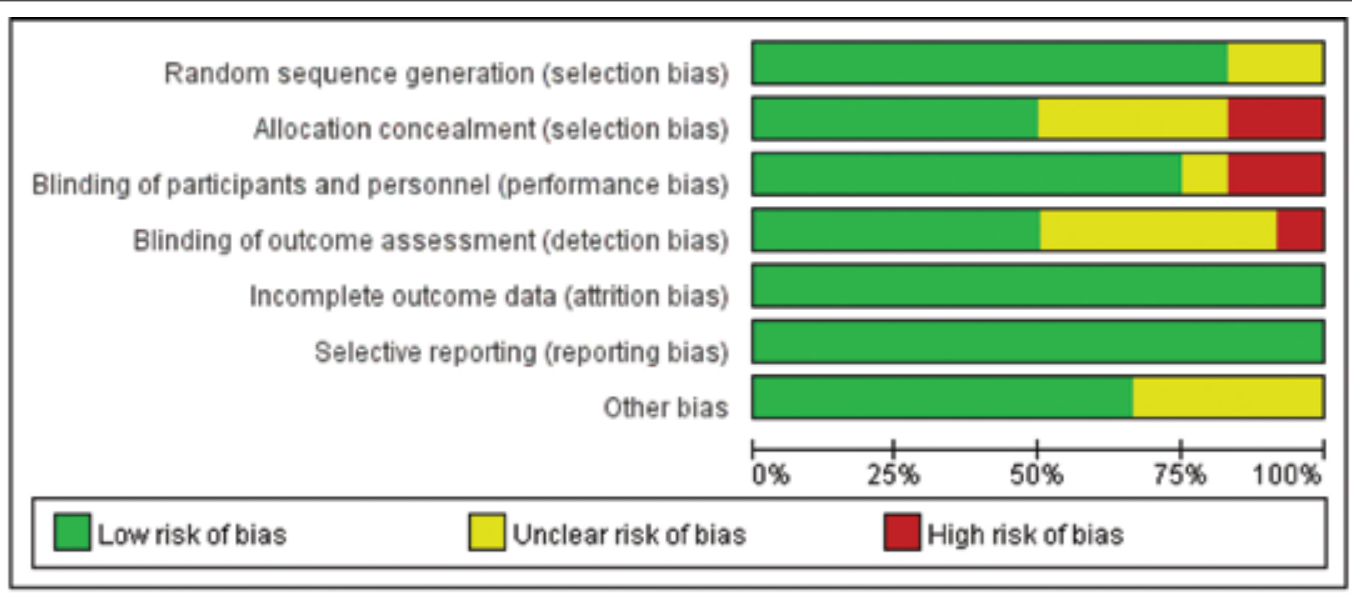

Fig. 2. Quality evaluation of summary of included studies.

\section{Quality Assessment}

Based on the Cochrane Handbook 5.1 Assessment Tool, Figs. 2 and 3 show the risk of bias among studies, which were judged by the 7 criteria. Results showed that most of the trials had reported a random design method but few reported an allocation concealment scheme; some of the trials reported a detailed blind design.

\section{Meta-analysis Results}

\section{Pain Score Analysis}

1. Comparing PRF with the control group, a total of 3 articles reported changes in pain score after one week.

Figure 4 shows that there is a low heterogeneity between the trials after one week (Chi2 $=3.78,12=47 \%$ ). 


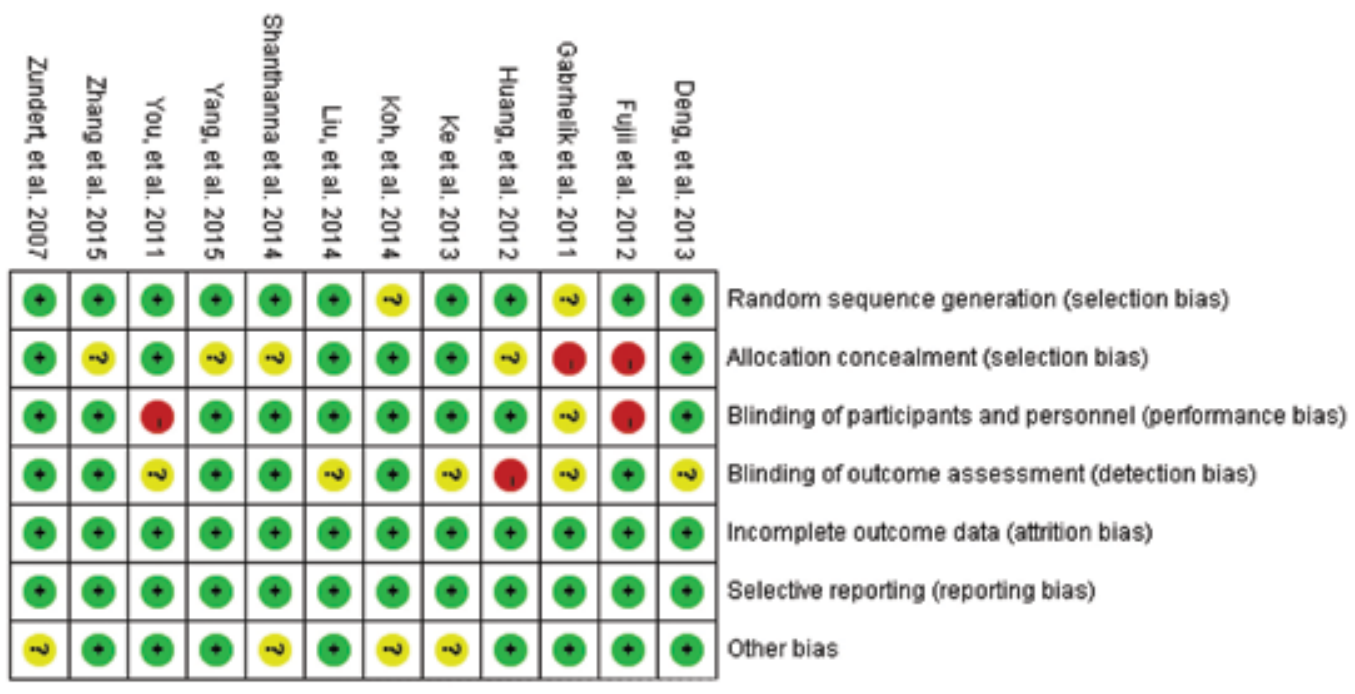

Fig. 3. Quality evaluation of included studies.

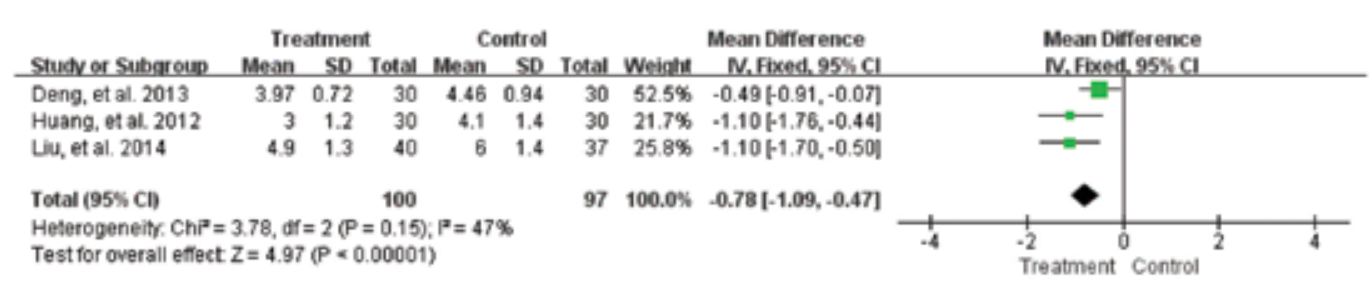

Fig. 4. Comparison of pain score between treatment group and control group after one week.

Therefore the fixed-effect model was used. PRF showed significant treatment effects on the pain score [MD $=-0.78,95 \% \mathrm{Cl}(-1.09,-0.47), P<0.00001]$, but caution should be exercised while drawing conclusions. The results showed that compared with the control group, PRF had a better analgesic effect. As a rule of thumb, tests for funnel plot asymmetry should only be used when there are at least 10 studies included in the meta-analysis, so we did not have a test for funnel plot asymmetry in this analysis.

2. Comparing PRF with the control group, a total of 4 articles reported changes in pain score after one month.

Figure 5 shows that there is a low heterogeneity between the trials after one month (Chi2 $=4.45,12=$
$33 \%$ ). Therefore the fixed-effect model was used. PRF showed significant treatment effects on the pain score [MD $=-0.87,95 \% \mathrm{Cl}(-1.19,-0.55), P<0.00001]$, but caution should be exercised while drawing conclusions. The results showed that compared with the control group, PRF had a better analgesic effect. As a rule of thumb, tests for funnel plot asymmetry should only be used when there are at least 10 studies included in the meta-analysis, so we did not have a test for funnel plot asymmetry in this analysis.

3. Comparing PRF with the control group, a total of 4 articles reported changes in pain score after 3 months.

Figure 6 shows that there is a high heterogeneity between the trials after 3 months (Chi2 = 13.21, $12=62 \%$ ). 


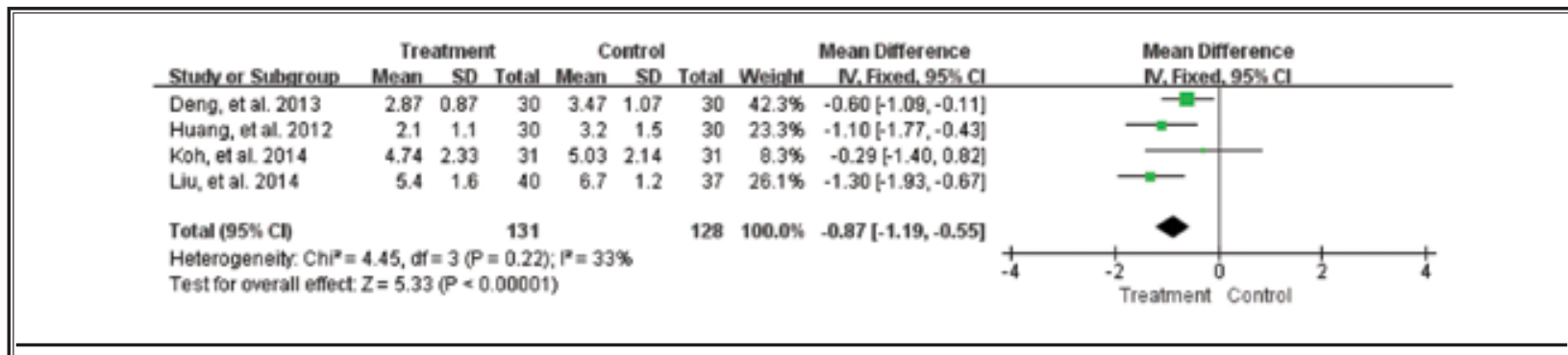

Fig. 5. Comparison of pain score between treatment group and control group after one month.

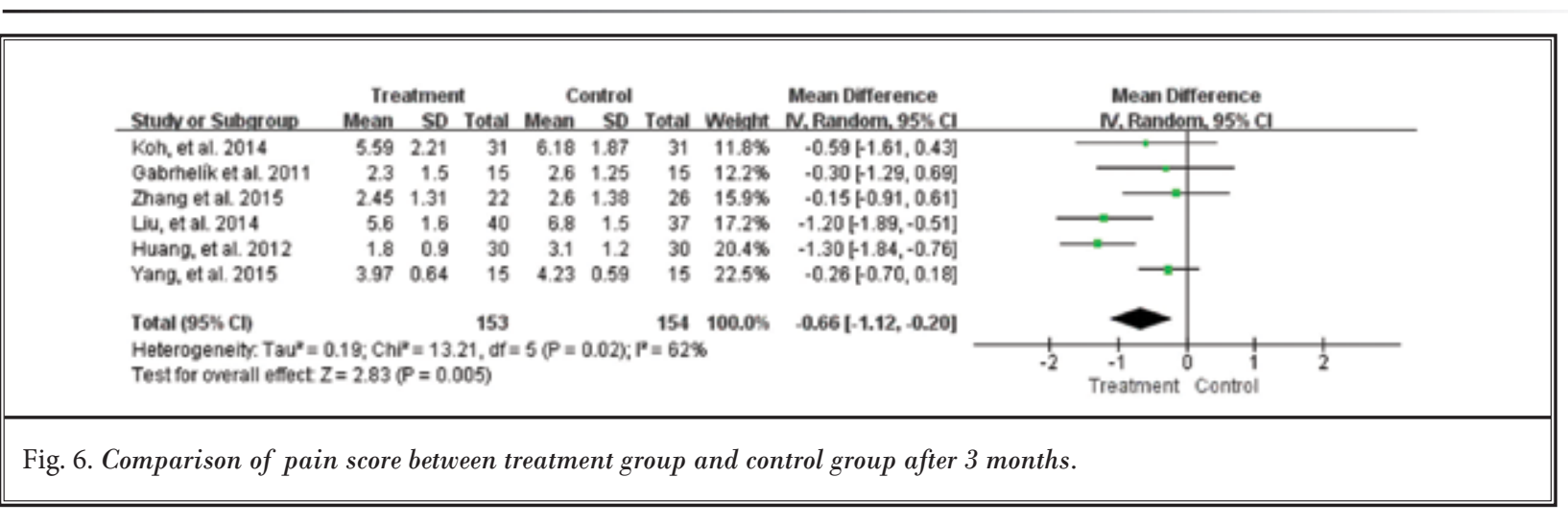

Therefore the random-effect model was used. PRF showed significant treatment effects on the pain score [MD $=-0.66$, $95 \% \mathrm{Cl}(-1.12,-0.20), P=0.005]$, but caution should be exercised while drawing conclusions. The results showed that compared with the control group, PRF had a better analgesic effect. Subgroup analyses were conducted based on the different NP diagnoses (PHN and radicular pain). In subgroup analyses, 2 studies involving 137 participants with a PHN diagnosis tended to have significant effects on pain score [MD $=-1.26,95 \% \mathrm{Cl}(-1.69,-0.84), P$ $<0.00001]$, indicating some heterogeneity between the different NP diagnoses $(12=0 \%), 4$ studies involving 170 participants with a radicular pain diagnosis showed no statistically significant on pain score [MD $=-0.28,95 \% \mathrm{Cl}$ $(-0.62,-0.06), P=0.10]$. In addition, the heterogeneity was significantly low in subgroup analyses (Fig. 7). As a rule of thumb, tests for funnel plot asymmetry should only be used when there are at least 10 studies included in the meta-analysis, so we did not have a test for funnel plot asymmetry in this analysis.

\section{Excellent and Good Rate/Efficiency Rate Analysis}

1. Comparing PRF with the control group, a total of 2 articles reported excellent and good rates after one day.
Figure 8 shows that there is a low heterogeneity between the trials after one day (Chi2 $=0.10,12=0 \%)$. Therefore the fixed-effect model was used. PRF showed significant treatment effects on the excellent and good rate $[\mathrm{OR}=3.35,95 \% \mathrm{Cl}(1.49,7.51), P<0.003]$, but caution should be exercised while drawing conclusions. As a rule of thumb, tests for funnel plot asymmetry should only be used when there are at least 10 studies included in the meta-analysis, so we did not have a test for funnel plot asymmetry in this analysis. The results suggested that the excellent and good rates of PRF are higher than those of the traditional treatments.

2. Comparing PRF with the control group, a total of 3 articles reported excellent and good rates after one month.

Figure 9 shows that there is a low heterogeneity between the trials after one month (Chi2 $=2.62,12=$ $24 \%$ ). Therefore the fixed-effect model was used. PRF showed significant treatment effects on the excellent and good rates $[\mathrm{OR}=3.32,95 \% \mathrm{Cl}(1.42,7.73), P=$ 0.005], but caution should be exercised while drawing conclusions. As a rule of thumb, tests for funnel plot asymmetry should only be used when there are at least 10 studies included in the meta-analysis, so we did not 


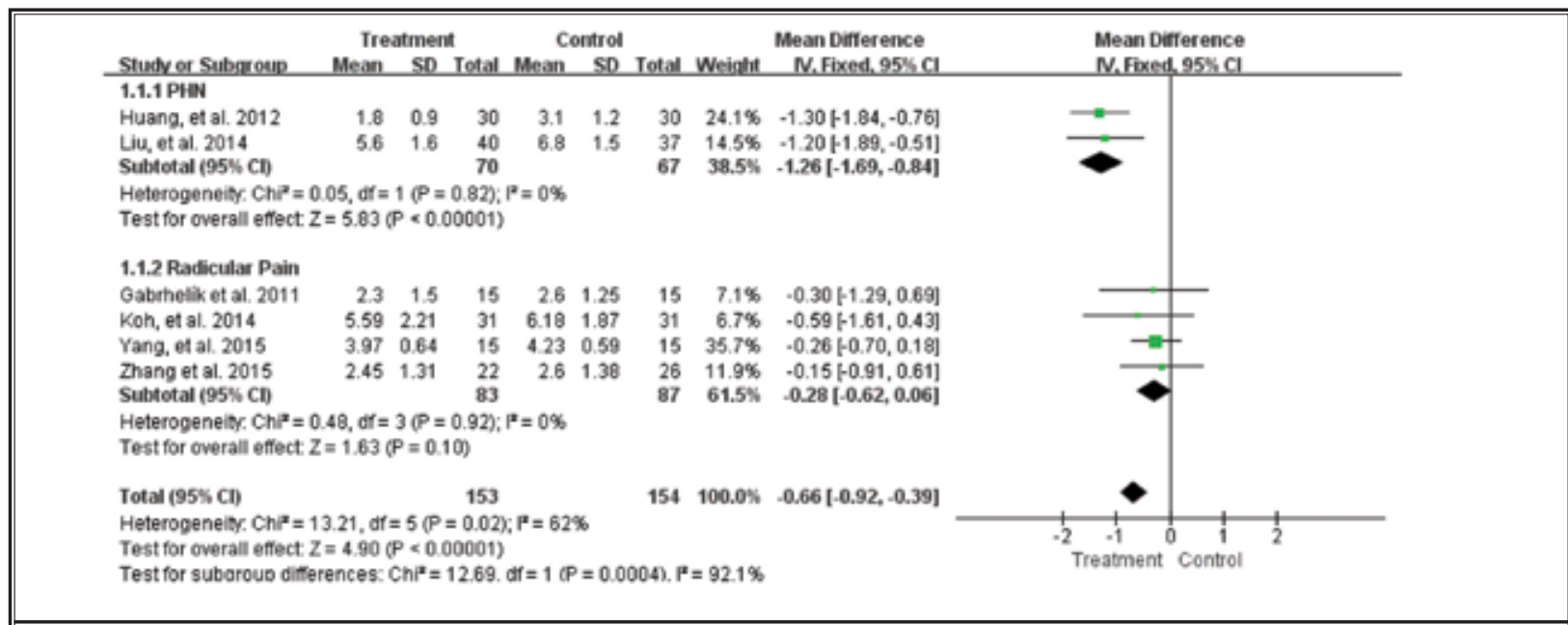

Fig. 7. Results of subgroup analysis of pain score changes after 3 months.

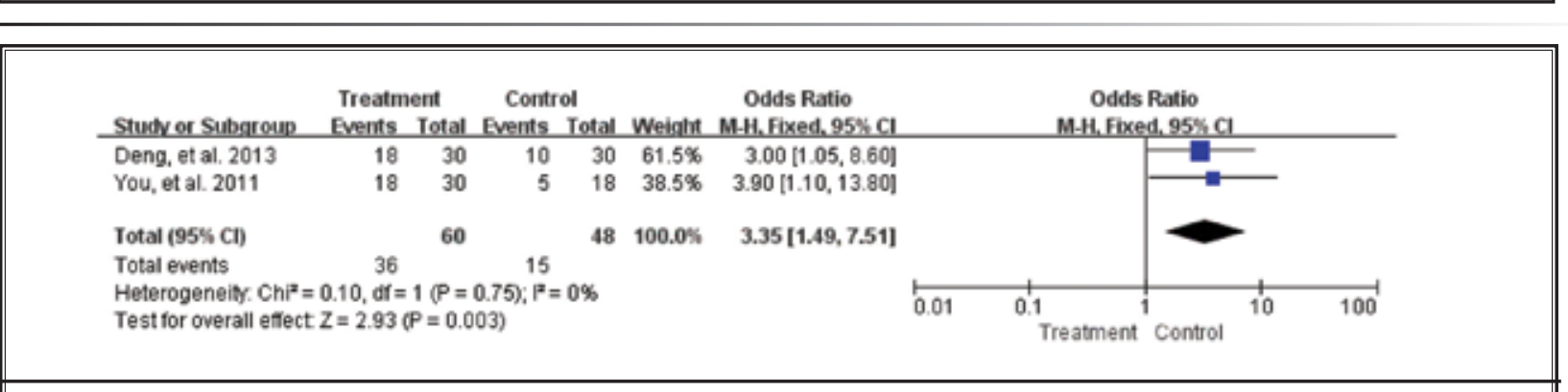

Fig. 8. Comparison of excellent and good rates between treatment group and control group after one day.

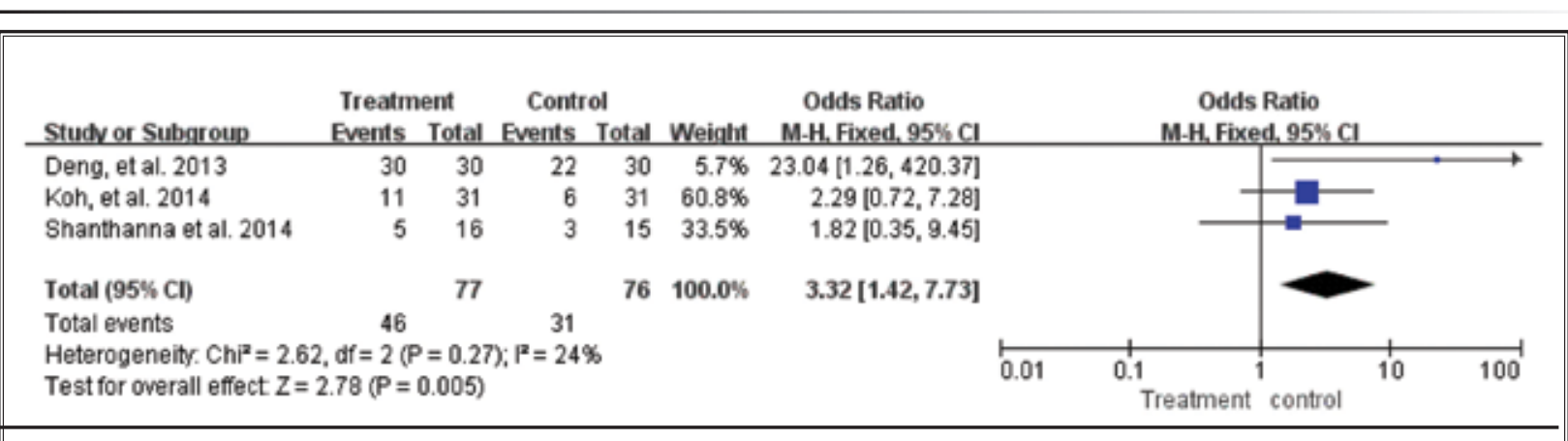

Fig. 9. Comparison of excellent and good rates between treatment group and control group after one month.

have a test for funnel plot asymmetry in this analysis. The results suggested that the excellent and good rates of PRF are higher than those of the traditional treatments.

3. Comparing PRF with the control group, a total of 2 articles reported an efficiency rate after one day.
Figure 10 shows that there is a low heterogeneity between the trials after one day (Chi2 $=0.04,12=$ $0 \%$ ). Therefore the fixed-effect model was used. PRF showed significant treatment effects on the efficiency rate $[\mathrm{OR}=7.78,95 \% \mathrm{Cl}(2.38,25.45), P=0.0007]$, but caution should be exercised while drawing conclusions. As a rule of thumb, tests for funnel plot asymmetry 


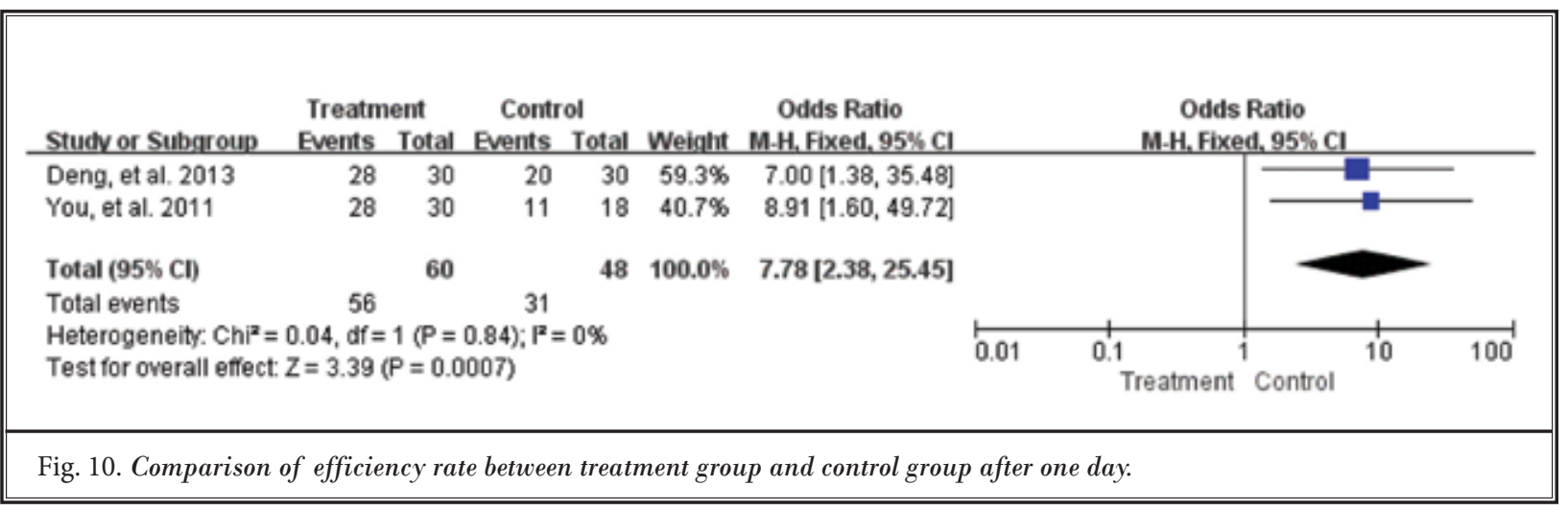

Table 2. The unanalyzed data of Deng et al's study.

\begin{tabular}{|c|c|c|c|c|c|}
\hline \multicolumn{6}{|c|}{ Deng et al. } \\
\hline Outcome A/B & 1 day & 1 week & 2 weeks & 1 month & $P$ value \\
\hline \multirow{2}{*}{ VAS } & & & $3.43 \pm 0.86$ & & \multirow{2}{*}{$=0.016$} \\
\hline & & & $4.03 \pm 1.00$ & & \\
\hline \multirow{2}{*}{ excellent and good rate } & & $80 \%$ & $86.7 \%$ & & \multirow{2}{*}{$<0.05$} \\
\hline & & $56.7 \%$ & $66.7 \%$ & & \\
\hline \multirow{2}{*}{ efficiency rate } & & $100 \%$ & $100 \%$ & & \multirow{2}{*}{$<0.05$} \\
\hline & & $93.3 \%$ & $93.3 \%$ & & \\
\hline \multirow{2}{*}{ SDS score } & $46.7 \pm 10.44$ & $41.43 \pm 9.66$ & $38.17 \pm 10.72$ & $41.23 \pm 9.80$ & \multirow{2}{*}{$<0.05$} \\
\hline & $52.8 \pm 9.91$ & $49.47 \pm 9.85$ & $47.13 \pm 10.85$ & $46.90 \pm 9.97$ & \\
\hline \multirow{2}{*}{ SAS score } & $46.13 \pm 10.74$ & $41.57 \pm 9.33$ & $37.06 \pm 8.73$ & $36.30 \pm 7.66$ & \multirow{2}{*}{$<0.05$} \\
\hline & $51.10 \pm 11.23$ & $48.27 \pm 10.57$ & $43.90 \pm 9.67$ & $41.10 \pm 8.70$ & \\
\hline
\end{tabular}

A/B: PRF/control group; SDS: Self-Rating Depression Scale; SAS: Self-Rating Anxiety Scale

should only be used when there are at least 10 studies included in the meta-analysis, so we did not have a test for funnel plot asymmetry in this analysis. The results suggested that the efficiency rates of PRF are higher than those of the traditional treatments.

\section{Other Data}

Due to the limitation of the included studies, some of the data were insufficient to complete the metaanalysis $(n<2)$, and for others the original data could not be obtained. We show the unanalyzed data here. All the studies were reported in A (PRF) and B (control) (Tables II - XII).

1. Table 2 shows that in Deng et al's study (26), PRF showed significant treatment effects on the pain score (2 weeks), excellent and good rate (one week, 2 weeks), efficiency rate (one week, 2 weeks), SDS (one day, one week, 2 weeks, one month), and SAS (one day, one week, 2 weeks, one month) $(P<0.05)$.
2. Table 3 shows that in Liu et al's study (24), PRF showed significant treatment effects on the SIS score (one day, one week, one month, 3 months) and SF-MPQ (one day, one week, one month, 3 months) $(P<$ 0.05).

3. Table 4 shows that in Huang et al's study (25), PRF showed significant treatment effects on dosage of oxycontin (one day, one week, one month, 3 months, 6 months) $(P<0.05)$.

4. Table 5 shows that in Gabrhelík et al's study (28), PRF showed significant treatment effects on the pain score (3 months, 9 months) and MQS (3 months, 9 months) $(P<0.05)$, but there were no statistically significant differences in the GPE $(P=0.272)$.

5. Table 6 shows that in Shanthanna et al's study (30), there were no statistically significant differences 
Table 3. The unanalyzed data of Liu et al's study.

\begin{tabular}{|c|c|c|c|c|c||}
\hline \multicolumn{7}{|c|}{ Liu et al } \\
\hline \multirow{2}{*}{ Outcome A/B } & 1 day & 1 week & 1 month & 3 months & P value \\
\hline \multirow{2}{*}{ SIS score } & $4.5 \pm 0.9$ & $4.8 \pm 1.1$ & $5.2 \pm 1.4$ & $5.5 \pm 1.5$ & $<0.05$ \\
\cline { 2 - 6 } & $5.5 \pm 1.2$ & $5.5 \pm 1.4$ & $6.8 \pm 1.1$ & $6.9 \pm 1.1$ & $<0.05$ \\
\hline \multirow{2}{*}{ SF-MPQ score } & $21 \pm 5$ & $22 \pm 6$ & $24 \pm 7$ & $26 \pm 7$ & $31 \pm 5$ \\
\cline { 2 - 5 } & $26 \pm 6$ & $27 \pm 7$ & $30 \pm 5$ & 2 & $<$ \\
\hline
\end{tabular}

SIS: Sleep Interference Score; SF-MPQ: Short Form of McGill Pain Questionnaire

Table 4. The unanalyzed data of Huang et al's study.

\begin{tabular}{|c|c|c|c|c|c|c||}
\hline \multicolumn{9}{|c|}{ Huang et al } \\
\hline Outcome & 1 day & 1 week & 1 month & 3 months & 6 months & P value \\
\hline \multirow{2}{*}{ Oxycontin A/B } & $17.6 \pm 5.4$ & $12.4 \pm 3.8$ & $5.1 \pm 1.6$ & $6.0 \pm 1.3$ & $4.2 \pm 0.9$ & $<0.05$ \\
\cline { 2 - 8 } & $35.6 \pm 8.5$ & $42.3 \pm 8.9$ & $18.6 \pm 4.3$ & $10.7 \pm 2.4$ & $8.1 \pm 1.6$ & $<$ \\
\hline
\end{tabular}

Table 5. The unanalyzed data of Gabrhelik et al's study.

\begin{tabular}{|c|c|c|c|}
\hline \multicolumn{4}{|c|}{ "Gabrhelík et al } \\
\hline Outcome A/B & 3 months & 9 months & $P$ value \\
\hline \multirow{2}{*}{ Pain score } & & $3.1[2-5]^{* * *}$ & \multirow{2}{*}{$\begin{array}{c}* * * P<0.001 \\
{ }^{*} P<0.05\end{array}$} \\
\hline & & $4.3[2-6]^{*}$ & \\
\hline \multirow{2}{*}{ MQS } & $3.2[0-11.4]^{* * *}$ & $6.8\left[\begin{array}{lll}0 & 1 & 1.4\end{array}\right]^{\star \star}$ & \multirow{2}{*}{$\begin{aligned}{ }^{* * *} P & <0.001 \\
{ }^{* *} P & <0.01\end{aligned}$} \\
\hline & $4.8[0-12.8]^{\star \star *}$ & $6.8[0-14.8]^{\star \star}$ & \\
\hline \multirow{2}{*}{ GPE } & & $9 / 15$ & \multirow{2}{*}{$P=0.272$} \\
\hline & & $5 / 15$ & \\
\hline
\end{tabular}

MQS: Medication Quantification Scale; GPE: Global Perceived Effect

Table 6. The unanalyzed data of Shanthanna et al's study.

\begin{tabular}{|c|c|c|c|c|c|c||}
\hline \multicolumn{7}{|c|}{ Shanthanna et al } \\
\hline A-B & 1 day & 1 week & 1 month & 2 months & 3 months & $P$ value \\
\hline Pain score & $-1.68(-0.43,0.96)$ & $-0.37(-3.82,3.08)$ & $-0.61(-2.68,1.46)$ & $-1.15(-3.61,1.31)$ & $-0.75(-3.12,1.63)$ & $P>0.05$ \\
\hline ODI & & $-0.06(-0.24,0.12)$ & $-0.03(-0.17,0.11)$ & $-0.08(-0.22,0.06)$ & $-0.08(-0.22,0.07)$ & \\
\hline
\end{tabular}

ODI: Oswestry Disability Index

between PRF and the control group on the pain score or ODI $(P>0.05)$.

6. Table 7 shows that in Koh et al's study (21), there were no statistically significant differences between PRF and the control group on the excellent and good rate ( 2 months), efficiency rate ( 2 months, 3 months), $30 \%$ decrease in ODI (one month, 2 months, 3 months), increase in ODI (one month, 2 months, 3 months), $25 \%$ decrease in MQS (one month, 2 months, 3 months), increase in MQS (one month, 2 months, 3 months), $\geq 6$ points on GPE scale (one month, 2 months, 3 months), ODI (3 months), pain score (A-B) (3 months), ODI (A-B) (3 months), and MQS (A-B) (3 months) ( $P>0.05$ ); PRF showed significant treatment effects on the ODI (one month, 2 months) $(P<0.05)$.

7. Table 8 shows that in Ke et al's study (27), PRF showed significant treatment effects on the pain score ( 3 days, one week, 2 weeks, one month, 2 months, 6 months), dosage (one day, 3 days, one week, 2 weeks, one month), and SF-36 (one month, 2 months, 3 months, 6 months) $(P<0.05)$.

8. Table IX shows that in Fujii et al's study (31), PRF showed significant treatment effects on the pain score (one day, one week) $(P<0.05)$; the control 
Treatment of Neuropathic Pain Using Pulsed Radiofrequency

Table 7. The unanalyzed data of Koh et al's study.

\begin{tabular}{|c|c|c|c|c|}
\hline \multicolumn{4}{|c|}{ Koh et al } & \multirow{2}{*}{$P$ value } \\
\hline $\mathbf{A} / \mathbf{B}$ & 1 month & 2 months & 3 months & \\
\hline \multirow{2}{*}{ excellent and good rate } & & 6/31 (19.4\%) & & \multirow{14}{*}{$\mathrm{A} / \mathrm{B} P>0.05$} \\
\hline & & $4 / 31(12.9 \%)$ & & \\
\hline \multirow{2}{*}{ efficiency rate } & & $16 / 31(51.6 \%)$ & $13 / 31(41.9 \%)$ & \\
\hline & & $12 / 31(38.7 \%)$ & $7 / 31(22.6 \%)$ & \\
\hline \multirow{2}{*}{$30 \%$ decrease in ODI } & $14 / 31(45.2 \%)$ & $11 / 31(35.5 \%)$ & $8 / 31(25.8 \%)$ & \\
\hline & $10 / 31(32.3 \%)$ & $7 / 31(22.6 \%)$ & $6 / 31(19.4 \%)$ & \\
\hline \multirow{2}{*}{ Increase in ODI } & $4 / 31(12.9 \%)$ & $3 / 31(9.7 \%)$ & $3 / 31(9.7 \%)$ & \\
\hline & $5 / 31(16.1 \%)$ & $8 / 31(25.8 \%)$ & $7 / 31(22.6 \%)$ & \\
\hline \multirow{2}{*}{$25 \%$ decrease in MQS } & 0 & $1 / 31(3.2 \%)$ & $6 / 31(19.4 \%)$ & \\
\hline & 0 & $2 / 31(6.5 \%)$ & $6 / 31(19.4 \%)$ & \\
\hline \multirow{2}{*}{ Increase in MQS } & 0 & $1 / 31(3.2 \%)$ & $4 / 31(12.9 \%)$ & \\
\hline & 0 & $4 / 31(12.9 \%)$ & $9 / 31(29.0 \%)$ & \\
\hline \multirow{2}{*}{$\geq 6$ points on GPE scale } & & $14 / 31(45.2 \%)$ & & \\
\hline & & $7 / 31(22.6 \%)$ & & \\
\hline \multirow{2}{*}{ ODI } & $35.36(30.58-40.14)$ & $35.07(30.24-39.90)$ & $37.62(32.67-42.57)$ & \multirow{2}{*}{${ }^{*} P>0.05 \mathrm{~A} / \mathrm{B}$} \\
\hline & $34.06(28.33-39.79$ & $36.48(30.76-42.21)$ & $37.99(32.53-43.44)^{*}$ & \\
\hline Pain score (A-B) 3 month & & & $0.331(-0.252$ to 0.914$)$ & \multirow{6}{*}{${ }^{*} P<0.05 \mathrm{~A} / \mathrm{B}$} \\
\hline Pain score (A-baseline) 3 month & & & $-0.813(-1.579--0.046)^{*}$ & \\
\hline ODI (A-B) 3 month & & & $2.134(-4.316$ to 8.584$)$ & \\
\hline ODI (A-baseline) 3 month & & & $-3.655(-9.585-2.276)$ & \\
\hline MQS (A-B) 3 month & & & $0.536(-1.927$ to 2.999$)$ & \\
\hline MQS (A-baseline) 3 month & & & $-0.197(-1.530-1.137)$ & \\
\hline
\end{tabular}

ODI: Oswestry Disability Index; MQS: Medication quantification scale

group showed significant treatment effects on the pain score (3 months, 6 months, 12 months) $(P<$ $0.05)$; there were no statistically significant differences between PRF and the control group on the pain score (one month) $(P>0.05)$.

9. Table 10 shows that in Van Zundert et al's study (29), there were no statistically significant differences between PRF and the control group on the pain medication (3 months) and SF-36 (3 months); PRF showed significant treatment effects on the GPE (one month, 3 months, 6 months) $(P<0.05)$.

10. Table 11 shows that in Yang et al's study (32), PRF showed significant treatment effects on dosage of aspirin (one month, 2 months, 6 months) $(P<0.05)$.

\section{Side Effects and Complications}

Table 12 shows the side effects and complications of the included studies.

\section{Discussion}

NP is a result of a primary lesion or dysfunction of the peripheral or central nervous system. A range of disorders of the peripheral nervous system-such as postherpetic neuralgia, trigeminal neuralgia, lumbar radicular pain, lumbosacral radicular pain, and cervical radicular pain-and a series of neuropathies are included under the term. Its prominent symptoms in patients are allodynia and hyperalgesia (3). As mechanisms of NP are unknown, its treatment is challenging. Analgesics, nonsteroidal anti-inflammatory drugs, physical therapy/rehabilitation, and a surgical approach can be used to address this issue (34). However, the evidence regarding the efficiency of these treatments and their superiority over one another is limited (6). The long duration of NP seriously influences patients' quality of life and causes them a huge economic burden.

RF procedures are an important part of complex, minimally invasive treatments for chronic pain condi- 
Table 8. The unanalyzed data of Ke et al's study.

\begin{tabular}{|c|c|c|c|c|c|c|c|}
\hline \multicolumn{7}{|c|}{ Ke et al } & \multirow[b]{2}{*}{$P$ value } \\
\hline Outcome & 3 days & 1 week & 2 weeks & 1 month & 2 months & 6 month & \\
\hline \multirow[t]{2}{*}{ VAS $\mathrm{A}<\mathrm{B}$} & $\mathrm{A}<\mathrm{B}$ & $\mathrm{A}<\mathrm{B}$ & $\mathrm{A}<\mathrm{B}$ & $\mathrm{A}<\mathrm{B}$ & $\mathrm{A}<\mathrm{B}$ & $\mathrm{A}<\mathrm{B}$ & $P<0.001$ \\
\hline & 1 day & 3 days & 1 week & 2 weeks & 1 month & $P$ value & \\
\hline Dosage & $A<B$ & $A<B$ & $A<B$ & $A<B$ & $A<B$ & $P<0.001$ & \\
\hline \multirow[t]{2}{*}{ SF-36 } & 1 month & 2 months & 3 months & 6 months & $P$ value & & \\
\hline & $A>B$ & $A>B$ & $\mathrm{~A}>\mathrm{B}$ & $\mathrm{A}>\mathrm{B}$ & $P<0.05$ & & \\
\hline
\end{tabular}

SF-36: the MOS 36-item short from health survey

Table 9. The unanalyzed data of Fujii et al's study.

\begin{tabular}{|c|c|c|c|c|c|c||}
\hline \hline \multicolumn{7}{|c|}{ Fujii et al (VAS) } \\
\hline Time & 1 day & 1 week & 1 month & 3 months & 6 months & 12 months \\
\hline Status & $\mathrm{A}<\mathrm{B}$ & $\mathrm{A}<\mathrm{B}$ & & $\mathrm{A}>\mathrm{B}$ & $\mathrm{A}>\mathrm{B}$ & $\mathrm{A}>\mathrm{B}$ \\
\hline$P$ & $P<0.05$ & $P<0.05$ & $P>0.05$ & $P<0.05$ & $P<0.05$ & $P<0.05$ \\
\hline
\end{tabular}

Table 10. The unanalyzed data of Zundert et al's study.

\begin{tabular}{|l|c|c|c|}
\hline Zundert et al & \multicolumn{2}{|c|}{ Equal } & Lower \\
\hline \multirow{2}{*}{ Pain medication (3 months) } & Higher & $4 / 11$ & $6 / 11$ \\
& $1 / 11$ & $3 / 12$ & $4 / 11$ \\
\hline & $5 / 12$ & $\mathbf{3}$ months & $\mathbf{6}$ months \\
\hline \multirow{2}{*}{ GPE } & $\mathbf{1}$ month & $9 / 11$ & $7 / 11$ \\
& $7 / 11$ & $4 / 12$ & $2 / 12$ \\
\hline SF-36 & $5 / 12$ & $\mathbf{3}$ months & $\mathbf{6}$ months \\
\hline & $\mathbf{1}$ month & A > B & \\
\hline$P<\mathbf{0 . 0 5}$ & & & \\
\hline
\end{tabular}

GPE: Global Perceived Effect; SF-36: the MOS 36-item short from health survey

Table 11. The unanalyzed data of Zhang et al's study.

\begin{tabular}{|l|l|l|l|l|}
\hline \hline Outcome & 1 month & 2 months & 6 months & P value \\
\hline Aspirin & $3.93 \pm 1.9$ & $3.40 \pm 1.54$ & $3.73 \pm 1.33$ & $P<0.05$ \\
\cline { 1 - 2 } A/B & $5.40 \pm 1.92$ & $5.40 \pm 1.8$ & $6.13 \pm 1.88$ & \\
\hline
\end{tabular}

tions and are used for reducing noxious transmission in the nervous system. PRF is a pain treatment modality used to manage pain in clinical practice; it has been associated with several advantages, including improved safety, easy application, and fewer side effects than CRF (4). The mechanism of PRF is yet to be elucidated. Results of experiments involving animals have suggested that PRF may change the expression of c-fos in laminae I and II of the dorsal horn $(35,36)$. Mikeladze et al (17) showed that PRF appeared to interrupt signals only in unmyelinated $C$ fibers while leaving myelinated delta fibers functional to transmit pain signals. PRF is consid- ered to induce an electric field in the regions of the dorsal root ganglion and influence local neuronal function (8). The results of previous experiments collectively suggested that PRF appeared to provide neuromodulation in response to painful stimuli without changing the morphology of motor and sensitive fibers; it probably works with a temperature independent pathway mediated by changing electric fields (37).

Since PRF does not produce sufficient heat around the probe or the tissue to damage nerves, there is no risk of deafferentation pain. A large number of studies have shown that PRF has an analgesic effect in the 
Table 12. The side effects and complications of different studies.

\begin{tabular}{|l|l|}
\hline Study & Description \\
\hline Liu et al & $\begin{array}{l}\text { Liu et al reported that in the control group, 4 participants had a local swelling, symptoms resolved after 1 - 3 days; in the } \\
\text { treatment group, 5 participants had a local swelling, symptoms resolved after 1 - 3 days, and 6 participants had a slightly } \\
\text { decreased innervation feeling, symptoms resolved after 1 - 3 weeks. }\end{array}$ \\
\hline Gabrhelík et al & Gabrhelík et al reported that 3 patients (10\%) had pain at the injection site for longer than one day. \\
\hline Shanthanna et al & $\begin{array}{l}\text { Shanthanna et al reported that 2 patients in each group had a headache and a transient increase in back pain, which did } \\
\text { not last beyond one day. }\end{array}$ \\
\hline Koh et al & $\begin{array}{l}\text { Koh et al reported that several patients reported temporary pain during needle insertion and paresthesia during sensory } \\
\text { stimulation, which was tolerable and did not require additional medications or discontinuation of the procedure. Six } \\
\text { patients in the PRF group and 4 patients in the control group complained of pain aggravation that presented for 2 - 3 } \\
\text { days, but spontaneous relief occurred without any sequelae. }\end{array}$ \\
\hline Ke et al & $\begin{array}{l}\text { Ke et al reported that bradycardia was found in one patient from the PRF group. This patient's heart rate fell to } 45 \text { beats } \\
\text { per minute, and returned to 60 to 70 beats per minute when the PRF was stopped. }\end{array}$ \\
\hline Summary & $\begin{array}{l}\text { The included studies did not report any serious side effects or complications related to the treatment. Pain, paresthesia, } \\
\text { or subcutaneous hematoma at the injection site may happen during the PRF. There might be an increased low back pain } \\
\text { or headache after the PRF after a short time. Very few people would suffer a pneumothorax or bradycardia. }\end{array}$ \\
\hline
\end{tabular}

treatment of NP, Ren (38) reported a > 50\% remission in $80 \%$ of patients after PRF treatment, suggesting that PRF has a good treatment effect for NP. Shabat et al (7) explained that $86 \%$ of patients reported an improvement in pain after one month, while 2 patients remained pain free, 7 patients had good results, and 11 patients had moderate results after 6 months. However, there is a lack of meta-analysis regarding the effectiveness and clinical utility of PRF for the treatment of NP.

In this study, a meta-analysis was conducted including 12 studies. The following outcomes were measured: (1) pain score (2) excellent and good rate/ efficiency rate.

\section{PHN}

The results of pain scores and excellent and good rate/efficiency rate suggested that PRF appeared to have beneficial effects on PHN relief after one week, one month, and 3 months $(P<0.05)$. The current results suggest that PRF might work better in sensory conduction, which has a better analgesic effect on PHN patients. In addition, PRF showed significant treatment effects on the pain score in 3 months, which suggested that for the treatment of NP, PRF has a better analgesia duration on PHN; it is very important for reducing the economic burden of patients and reducing the dose of analgesic drugs, and it improves patients' quality of life. Our results also support the results of previous studies, such as those of Kim et al (39), who reported that in 59 cases of PHN, there was excellent pain relief (about $55 \%$ ) at 4 weeks after PRF, and of a prospective study of occipital neuralgia by Vanelderen et al (40), who re- ported a decreased VAS with PRF treatment. In a word, PRF has a good analgesic effect for the treatment of $\mathrm{PHN}$ over a short time, and its analgesic effect is much better than traditional treatment (8).

Due to the limitation of the included studies, the data of some studies were insufficient to complete the meta-analysis $(n<2)$, and the original data could not be obtained for others studies. By observing data, most of the included studies showed that PRF had a better significant treatment effect than traditional treatments, just like our meta-analysis results.

\section{Radicular Pain}

The results of pain scores showed no statistically significant differences between the PRF and control groups in subgroup analysis ( 3 months) $(P>0.05)$. The results suggested that PRF was not associated with significantly better therapeutic effects on radicular pain, and that PRF was associated with effects similar to those of traditional treatments. This conclusion was also supported by other studies. For example, Shanthanna et al (30) reported no significant differences in VAS scores and ODIs between the PRF and control groups. Additionally, Koh et al (21) reported no statistically significant differences between the PRF and control groups regarding the excellent and good rates, efficiency rates, 30\% decrease in ODI, increase in ODI, $25 \%$ decrease in MQS, and increases in MQS, ODI, and pain scores. Furthermore, Van Zundert et al (29) reported no statistically significant differences between the PRF and control groups on the pain medication and SF-36 scores. Collectively, the aforementioned results 
suggested that PRF was not associated with significantly better therapeutic effects on radicular pain, and that PRF was associated with effects similar to those of traditional treatments. Compared with the traditional methods, PRF had no special effects in radicular pain. Despite this, the simple and facile characteristics of PRF were associated with advantages over long-term drug treatments.

\section{Other Data}

It is also noteworthy that Makharita and Amr (41) found more robust and significant treatment effects in the control group as compared with the PRF group during 4 to 12 months of the treatment. Additionally, Fujii et al (31) reported that from 3 to 12 months, the control group tended to demonstrate better pain relief. The aforementioned results indicated that PRF may not have a significant treatment effect on NP in the long term, suggesting that PRF has a limited duration of efficacy. Because the effects of PRF were observed to wear off, repeated treatments may be required to ensure a continuous analgesic effect. This assertion has been supported by the results of other studies, such as that of Boxem et al (42), reporting that pain remission in those receiving PRF treatment lasted for only 9.89 months in patients with lumbosacral radicular pain. That experimental result showed that PRF had a limited duration of efficacy and therefore required repeated treatments. It also provided a reference for physicians who need to make decisions regarding the choice of treatment options.

In brief, PRF has different effects depending on the types of NP, and PRF treatment may require repeated administrations over longer durations. It is also an effective and safe short-term therapeutic alternative for the treatment of PHN; however, repeated PRF treatments have been associated with limitations for those with high recurrence rates over long durations.

\section{Side Effects and Complications}

Our results showed that the included studies did not report any serious side effects or complications related to the treatment. A pain, paresthesia, or subcutaneous hematoma often appeared at the injection site. It seemed that PRF is a safe therapeutic alternative for the treatment of NP.

\section{Quality Assessment Scoring}

Our results suggest that most of the papers on PHN studies have higher literature quality than those on radicular pain studies. It is well known that radicular pain is associated with compression of the peripheral nerves including motor and sensory nerves. However varying extent of compression would typically lead to significantly varying senses among individual patients with radicular pain, contributing to high heterogeneity of the studies. In contrast, as PHN is simply caused by the herpes zoster virus, the patients would have similar symptoms and intensity of pain, contributing to low heterogeneity and hence higher quality of the relevant studies. These may be the primary reasons for the difference in the literature quality scores for the 2 types of pain.

\section{Limitations}

Although we repeatedly tested the key words and used a manual method to prevent the loss of studies, due to the limitation of the included studies, some of the data were insufficient to complete the metaanalysis, and we were unable to obtain the original data for some studies; 2 . Some studies did not report the random and blind design, which decreased the quality of the current study. Therefore, large-scale, multiple-term, high-quality RCTs would be necessary to prove or disprove the significant advantages or disadvantages.

\section{Conclusion}

PRF did not have a better effect on radicular pain, and PRF is an effective and safe therapeutic alternative for the analgesia of PHN. However, for a high recurrence rate over a long period, repeated PRF treatment has limitations. 


\section{References}

1. Neuropathic Pain: The Pharmacological Management of Neuropathic Pain in Adults in Non-specialist Settings. National Institute for Health and Clinical Excellence: Guidance, London, 2013.

2. Bouhassira D, Lanteri-Minet $M$, Attal N, Laurent B, Touboul C. Prevalence of chronic pain with neuropathic characteristics in the general population. Pain 2008; 136:380-387.

3. Jensen TS, Finnerup NB. Allodynia and hyperalgesia in neuropathic pain: Clinical manifestations and mechanisms. The Lancet Neurology 2014; 13:924-935.

4. Ozsoylar O, Akcali D, Cizmeci P, Babacan A, Cahana A, Bolay $H$. Percutaneous pulsed radiofrequency reduces mechanical allodynia in a neuropathic pain model. Anesthesia and Analgesia 2008; 107:1406-1411.

5. Dworkin $\mathrm{RH}, \mathrm{O}^{\prime}$ Connor $\mathrm{AB}$, Backonja $M$, Farrar JT, Finnerup NB, Jensen TS, Kalso EA, Loeser JD, Miaskowski C, Nurmikko TJ, Portenoy RK, Rice AS, Stacey BR, Treede RD, Turk DC, Wallace MS Pharmacologic management of neuropathic pain: Evidence-based recommendations. Pain 2007; 132:237-251.

6. Dworkin $\mathrm{RH}$, O'Connor AB, Audette J, Baron R, Gourlay GK, Haanpaa ML, Kent JL, Krane EJ, Lebel AA, Levy RM, Mackey SC, Mayer J, Miaskowski C, Raja SN, Rice AS, Schmader KE, Stacey B, Stanos S, Treede RD, Turk DC, Walco GA, Wells CD. Recommendations for the pharmacological management of neuropathic pain: An overview and literature update. Mayo Clinic Proceedings 2010; 85:S3-S14.

7. Shabat S, Pevsner Y, Folman Y, Gepstein $R$. Pulsed radiofrequency in the treatment of patients with chronic neuropathic spinal pain. MIN 2006; 49:147-149.

8. Simopoulos TT, Kraemer J, Nagda JV, Aner M, Bajwa ZH. Response to pulsed and continuous radiofrequency lesioning of the dorsal root ganglion and segmental nerves in patients with chronic lumbar radicular pain. Pain Physician 2008; 11:137-144.

9. Erdine S, Ozyalcin NS, Cimen A, Celik M, Talu GK, Disci R. Comparison of pulsed radiofrequency with conventional radiofrequency in the treatment of idiopathic trigeminal neuralgia. European Journal of Pain 2007; 11:309-313.

10. Erdine S, Yucel A, Cimen A, Aydin S, Sav A, Bilir A. Effects of pulsed versus conventional radiofrequency current on rabbit dorsal root ganglion morphology.
European Journal of Pain 2005; 9:251-256.

11. Kroll HR, Kim D, Danic MJ, Sankey SS Gariwala M, Brown M. A randomized, double-blind, prospective study comparing the efficacy of continuous versus pulsed radiofrequency in the treatment of lumbar facet syndrome. Journal of Clinical Anesthesia 2008; 20:534-537.

12. Sluijter ME, Cosman ER, Rittman WB. The effects of pulsed radiofrequency fields applied to the dorsal root ganglion: A preliminary report. Pain Clin 1998; 11:109-117.

13. Munglani R. The longer term effect of pulsed radiofrequency for neuropathic pain. Pain 1999; 80:437-439.

14. Pockett S. Spinal cord synaptic plasticity and chronic pain. Anesthesia and Analgesia 1995; 80:173-179.

15. Sandkühler J, Chen JG, Cheng G, Randic M. Low-frequency stimulation of afferent Adelta-fibers induces long-term depression at primary afferent synapses with substantia gelatinosa neurons in the rat. The Journal of Neuroscience 1997; 17:6483-6491.

16. Martin DC, Willis ML, Mullinax LA, Clarke NL, Homburger JA, Berger $\mathrm{IH}$. Pulsed radiofrequency application in the treatment of chronic pain. Pain Practice 2007; 7:31-35.

17. Mikeladze G, Espinal R, Finnegan R, Routon J, Martin D. Pulsed radiofrequency application in treatment of chronic zygapophyseal joint pain. The Spine Journal 2003; 3:360-362.

18. Fukui S, Nitta K, Iwashita $\mathrm{N}$, Tomie $\mathrm{H}$, Nosaka S, Rohof O. Intradiscal pulsed radiofrequency for chronic lumbar discogenic low back pain: A one year prospective outcome study using discoblock for diagnosis. Pain Physician 2013; 16:E435-E442.

19. Liberati A, Altman DG, Tetzlaff J, Mulrow C, Gøtzsche PC, loannidis JP, Clarke M, Devereaux PJ, Kleijnen J, Moher D. The PRISMA statement for reporting systematic reviews and meta-analyses of studies that evaluate health care interventions: Explanation and elaboration. Annals of Internal Medicine 2009; 151:W-65-W-94.

20. Zheng X. Guiding Principle of Clinical Research on New Drugs of Traditional Chinese Medicine. China Medic-Pharmaceutical Sciences and Technology Publishing House, Beijing, 2002, p 143.

21. Koh w, Choi SS, Karm MH, Suh JH, Leem JG, Lee JD, Kim YK, Shin J. Treatment of chronic lumbosacral radicular pain using adjuvant pulsed radiofrequency: A randomized controlled study. Pain Medicine 2015; 16:432-441.

22. Higgins J, Green S. Cochrane handbook for systematic reviews of Interventions Version 5.1. o. Updated March 2011. The Cochrane Collaboration, 2011.

23. You WD, Fu DG, Yu HY. A study of pulsed radiofrequency combined with never block in the treatment of postherpeticn euralgia (Chin). Practical Journal of Cardiac Cerebral Pneumal and Vascular Disease 2011; 19:477-479.

24. Liu JZ, Shi KM, Ma WT, Zheng BS. Efficacy of pulsed radiofrequency in the dorsal root ganglia for the treatment of patients with postherpetic neuralgia under the guidance of 3-dimension reconstruction CT (Chin). Pain Clinic Journal 2014; 10:170-174.

25. Huang QD, Gong QJ, Bo CJ, Liu XM, Chen JS, Lu ZH, Gao CR. Dosal root ganglion pulsed radiofrequency guided by DSA for postherpetic neuralgia (Chin). Journal of Practical Medicine 2012; 28:2187-2190.

26. Deng R. The clinical research of pulsed radiofrequency of dorsal root ganglion combine wtih epidural block in the theatment of post-herpetic neuralgia (Chin). Master's thesis, Luzhou Medical College, Luzhou, 2013.

27. Ke M, Yinghui F, Yi J, Xeuhua H, Xiaoming L, Zhijun C, Chao H, Yingwei W. Efficacy of pulsed radiofrequency in the treatment of thoracic postherpetic neuralgia from the angulus costae: A randomized, double-blinded, controlled trial. Pain Physician 2013; 16:15-25.

28. Gabrhelik T, Michalek P, Adamus M. Pulsed radiofrequency therapy versus greater occipital nerve block in the management of refractory cervicogenic headache - a pilot study. Prague Medical Report 2011; 112:279-287.

29. Van Zundert J, Patijn J, Kessels A, Lame I, van Suijlekom H, van Kleef M. Pulsed radiofrequency adjacent to the cervical dorsal root ganglion in chronic cervical radicular pain: A double blind sham controlled randomized clinical trial. Pain 2007; 127:173-182.

30. Shanthanna H, Chan P, McChesney J, Thabane L, Paul J. Pulsed radiofrequency treatment of the lumbar dorsal root ganglion in patients with chronic lumbar radicular pain: A randomized, placebo-controlled pilot study. Journal of Pain Research 2014; 7:47-55.

31. Fujii H, Kosogabe Y, Kajiki H. [Long- 
term effects of pulsed radiofrequency on the dorsal root ganglion and segmental nerve roots for lumbosacral radicular pain: a prospective controlled randomized trial with nerve root block]. Masui 2012; 61:790-793.

32. Yang $Y$, Ma K. Efficacy of pulsed radiofrequency on cervical 2-3 posterior medial branches in treating cervicogenic headache. Chinese Journal of Pain Medicine 2015; 21:266-269.

33. Zhang K, Zhu YQ, Zhu X, Chen JY. Imaging-guided pulsed-radiofrequency stimulation of medial branch of lumbar spinal nerve for the treatment of lumbar radicular pain. Journal of Interventional Radiology 2015; 24:502-504.

34. Perret D, Kim DS, Li KW, Luo ZD. Exposure of the dorsal root ganglion to pulsed radiofrequency current in a neuropathic pain model of peripheral nerve injury. Methods in Molecular Biology 2012; 851:275-284.
35. Higuchi Y, Nashold BS, Jr., Sluijter M, Cosman E, Pearlstein RD. Exposure of the dorsal root ganglion in rats to pulsed radiofrequency currents activates dorsal horn lamina I and II neurons. Neurosurgery 2002; 50:850-855; discussion 856.

36. Van Zundert J, de Louw AJ, Joosten EA, Kessels AG, Honig W, Dederen PJ, Veening JG, Vles JS, van Kleef M. Pulsed and continuous radiofrequency current adjacent to the cervical dorsal root ganglion of the rat induces late cellular activity in the dorsal horn. Anesthesiology 2005; 102:125-131.

37. Cahana A, Vutskits L, Muller D. Acute differential modulation of synaptic transmission and cell survival during exposure to pulsed and continuous radiofrequency energy. The Journal of Pain 2003; 4:197-202.

38. Ren YS. PCEA analgesia combined radiofrequency treatment of postherpetic neuralgia. Guide of China Medicine 2010; 8:28-30.
39. Kim YH, Lee CJ, Lee SC, Huh J, Nahm FS, Kim HZ, Lee MK. Effect of pulsed radiofrequency for postherpetic neuralgia. Acta Anaesthesiologica Scandinavica 2008; 52:1140-1143.

40. Vanelderen P, Rouwette $T$, De Vooght P, Puylaert M, Heylen R, Vissers K, Van Zundert J. Pulsed radiofrequency for the treatment of occipital neuralgia: A prospective study with 6 months of followup. Regional Anesthesia and Pain Medicine 2010; 35:148-151.

41. Makharita MY, Amr YM. Pulsed radiofrequency for chronic inguinal neuralgia. Pain Physician 2015;18:E147-155.

42. Van Boxem K, van Bilsen J, de Meij N, Herrler A, Kessels F, Van Zundert J, van Kleef $M$. Pulsed radiofrequency treatment adjacent to the lumbar dorsal root ganglion for the management of lumbosacral radicular syndrome: A clinical audit. Pain Medicine 2011; 12:1322-1330. 